\begin{tabular}{|l|l|l|}
\hline \multicolumn{2}{|c|}{ PublisherInfo } \\
\hline \hline PublisherName & $:$ & BioMed Central \\
\hline \hline PublisherLocation & $:$ & London \\
\hline \hline PublisherImprintName & $:$ & BioMed Central \\
\hline \hline
\end{tabular}

\title{
What is the best ventilation mode for patients with ARDS?
}

\begin{tabular}{|l|l|l||}
\hline \multicolumn{2}{|c|}{ ArticleInfo } \\
\hline \hline ArticleID & $:$ & 4214 \\
\hline \hline ArticleDOI & $:$ & $10.1186 /$ ccf-2000-5759 \\
\hline \hline ArticleCitationID & $:$ & 5759 \\
\hline \hline ArticleSequenceNumber & $:$ & 73 \\
\hline \hline ArticleCategory & $:$ & Paper Report \\
\hline ArticleFirstPage & $:$ & 1 \\
\hline \hline ArticleLastPage & $:$ & 3 \\
\hline \hline & & RegistrationDate : 2000-7-31 \\
\hline ArticleHistory & $:$ & OnlineDate \\
\hline \hline ArticleCopyright & $:$ & Current Science Ltd2000-7-31 \\
\hline \hline ArticleGrants & $:$ & \\
\hline \hline ArticleContext & $:$ & 1305422 \\
\hline \hline
\end{tabular}


Aff1 Royal North Shore Hospital, New South Wales, Australia

\section{Keywords}

Pressure controlled ventilation, volume controlled ventilation.

\section{Comments}

The authors concede that the higher incidence of renal failure may have influenced outcome in the volume-controlled ventilation (VCV) group, but found attractive the hypothesis that VCV induced the more severe systemic inflammatory response than pressure-controlled ventilation (PCV). The authors emphasise that the main difference between these two ventilatory modes was the inspiratory flow waveform profile and that previous studies have not suggested that this makes a significant contribution to outcome. The interesting thing about this study is that it suggests that PCV with an accelerating waveform is the treatment of choice for all patients with acute respiratory distress syndrome (ARDS). The authors concluded that the excess number of extrapulmonary organ failures in patients in the VCV group was responsible for the higher mortality rate, but that the development of multiple organ failure syndrome is unlikely to be related to the ventilatory mode utilised.

\section{Introduction}

The question addressed by this study was whether the hospital mortality of patients with ARDS would be influenced by the ventilatory mode used when a strategy of mechanical ventilation limiting inspiratory pressure is implemented.

\section{Methods}

The patients were randomly assigned to receive PCV or VCV with plateau inspiratory pressure limitation to $35 \mathrm{~cm}$ of water, saturation maintained at $89 \%-92 \%$ for the lowest possible $\mathrm{FIO}_{2}$ and a positive end expiratory pressure (PEEP) level that was never $<5 \mathrm{~cm}$ of water. Hypercapnia was accepted if a target of $\mathrm{PaCO}_{2} 35-45 \mathrm{mmHg}$ could not be achieved at the pre-set pressure limitation. An interesting addition to the protocol was the infusion of sodium bicarbonate if the $\mathrm{pH}$ was $<7.2$. If, after 
bicarbonate infusion, the $\mathrm{pH}$ remained $<7.2$ then the tidal volume in the $\mathrm{VCV}$ or the inspiratory pressure in the PCV group was increased.

\section{Results}

There were 42 patients in the VCV group and 37 in the PCV group. Although not statistically significant, there was a tendency towards a higher percentage of patients with shock as a risk factor for ARDS, and a trend towards a higher incidence of acute renal failure in the VCV group at the moment of randomisation. In-hospital mortality was significantly higher ( $78 \%$ vs $51 \%$ ) in the VCV group. The number of extrapulmonary organ failures was higher in the VCV group. There were no significant differences between the two groups for the incidence of paratrauma, the duration of mechanical ventilation, the length of stay in the ICU or the length of hospital stay.

\section{References}

1. Esteban A, Alia I, Gordo F, de Pablo R, Suarez J, Gonzalez G, Blanco J: Prospective randomized trial comparing pressure-controlled ventilation and volume-controlled ventilation in ARDS. Chest. 2000, 117: 1690-1696.

This PDF file was created after publication. 